which always surprises those who take it up by the fulness of its information and by the interest which it stimulates. There is no specific indication in the present volume as to what parts are derived from the original and what parts are due to Prof. Ward's careful editing; in any case, the result of the collaboration is a most admirable book.

\section{W. N. Shaw.}

\section{OUR BOOK SHELF.}

The Steam Turbine. By Robert M. Neilson. Second Edition. Pp. xvii + 294. (London : Longmans, Green and Co.) Price Ios. $6 d$. net.

THE history of the steam turbine previous to the reign of Parsons, whose first patents were applied for in I884, may be made out from chapters i. and ii. But descriptions of inventions in the language and with the illustrations usual in patent specifications are not quite what is expected from the author of such a book as this. There is an appendix giving the names and dates of all patents relating to steam turbines. The history and construction of the Parsons and the Laval turbines are given at some length, with the results of practical tests for power and consumption of steam, and the reader gets an opportunity of understanding the construction of modified forms which are now, under various names, coming into use. Students are anxious to examine good drawings and descriptions of the details of the Parsons turbine, and it would appear that these are difficult to obtain. The author of this book has given much information and many illustrations somewhat in the style made familiar to us in the engineering newspapers. Much more information is given about the Laval type of turbine. As to the theory of these turbines, the essentially important points seem to be ignored, and yet all the theory of any turbine known to anybody may be given very shortly indeed. There is a particularly interesting point in connection with the Laval turbine to which the author might have directed attention, namely, the exceedingly great speed reached by fluid at the end of an expanding mouthpiece. So far as we know, the reason for this has never been published, and yet any student of the papers of Osborne Reynolds ought to be able to give it readily.

The chapter on the propulsion of ships by turbines is interesting.

On the whole, the book is one that ought to be read by students; it is practically the only book on the subject, but we think that the author has not done so well with his materials as he might have done.

Whittaker's Electrical Engineer's Pocket Book. Edited by Kenelm Edgcumbe. Pp. viii +456 . (London: Whittaker and Co., Igo3.) Price $3 s .6 d$.

This little book differs in several respects from the ordinary type of pocket book; it possesses the usual features - a limp cover, round corners, gilt edges, and a weight quite unsuited to the pocket-which serve to characterise the " pocket book," but in the arrangement of the matter it rather resembles a small encyclo pædia. Each branch of electrical engineering is dealt with in a separate section or chapter, which may be read consecutively as if it were a brief treatise on the subject. The method has much to recommend it; the electrical engineer who comes across some problem in a branch with which he is not familiar can turn up the section dealing with that branch and read a summary of the whole subject; numerous references to recent papers will greatly help him in finding the particulars which he wants. There are, of course, also a number of tables of the constants more generally required. The treatment is not very even; thus whilst generating machinery-dynamos, alternators, and motors-receives full consideration in roo pages or more, only four pages are given to electric lamps and lighting, and the information given therein is quite inadequate. The diagrams and illustrations are clearer than those usually to be found in books of this class.

M. S.

Astronomischer Jahresbericht. By Walter F. Wislicenus. Band iv. Pp. xxxii +648 . (Berlin: Georg Reimer, 1903.)

THIs, the fourth issue of this most valuable and useful volume, contains the references and a brief summary of contents of the astronomical literature published last year. The work is of the same high standard as in former years, and casts great credit on the labours of Herr Wislicenus and his joint compilers. This yearbook is so well known to astronomers, and has been found so valuable by them, that it is hardly necessary to dwell either on the general arrangement of the subject or on the method of treatment. The main object of the compilers was to make as perfect a record as possible of all the published papers on this subject, yet to keep the book from becoming too bulky. This they have succeeded in doing, in spite of the fact that many of the abstracts of lengthy papers are very complete.

Now that the Royal Society has published the first annual issue of this branch of science (E. Astronomy) in the "International Catalogue of Scientific Literature," it seems possible that there will scarcely be room for both of these compilations, since the more perfect they become the more closely will they resemble each other. This question, however, the future will no doubt settle. There is, nevertheless, one main difference between them, in that the volume before us summarises the contents af each paper to which reference is made, while that of the "International Catalogue " is restricted to the bare references.

$$
\text { W. J. S. L. }
$$

Practical Management of Pure Yeast. By Alfred Jörgensen. Translated by R. Grey. Pp. viii +60 . (London: the Brewing Trade Review, r9o3.)

THis useful little work might have received with advantage a title better descriptive of its contents. It contains a condensed account of the biological methods which are employed in the author's well-known laboratory in the pure culture and analysis of alcohol. producing yeasts. According to the preface, the leading purpose of this treatise is to enlighten the so-called practical man in the methods of investigation employed by the zymotechnologist, so that in the future the practical man and the technologist may work together with better understanding at the many important and difficult problems which are encountered in the processes of the fermentation industries. No doubt the little book is well calculated to fulfil its object if only the practical man will read it, and we hope it will be in much demand for this purpose. But whatever may be the success of the book in this direction, it undoubtedly deserves the careful attention of all zymotechnologists, as it indicates the lines on which a well-known investigator of great experience is working with a view to the solution of many interesting and complicated problems in connection with the organisms of fermentation. The last words on the biological methods of analysis and the technical employment of pure cultures of yeast are still a very long way from being spoken, but as an advance towards this end we cordially recommend the work to the attention of all interested in the biological aspect of the fermentation industries.
A. J. B. No. 1775 , vOL. 69] 